\title{
Monitoring and targeting the sanitation poor: A multidimensional approach
}

\author{
Ricard Giné-Garriga and Agustí Pérez-Foguet
}

\begin{abstract}
Water, sanitation and hygiene (WaSH) are at the core of sustainable development. As we embark on a new round of global goals, namely the Sustainable Development Goals, a top priority is to address a coherent framework for monitoring these services. In the coming years, the sector will witness the development of a variety of multidimensional monitoring measures, albeit from different perspectives. This paper reviews the relevant literature and discusses the adequacy and applicability of one approach that is increasingly adopted for multidimensional poverty measurement at the household level, the AlkireFoster methodology. Drawing on this method, we identify and combine a set of direct household-related water and sanitation deprivations that batter a person at the same time. This new multidimensional measure is useful for gaining a better understanding of the context in which WaSH services are delivered. It captures both the incidence and intensity of WaSH poverty, and provides a new tool to support monitoring and reporting. For illustrative purposes, one small town in Mozambique is selected as the initial case study.
\end{abstract}

Keywords: Water and sanitation poverty; poverty measurement and reporting; multidimensional poverty; Sustainable Development Goals.

\section{Introduction}

Improving water and sanitation service delivery for billions of people is central to addressing many of today's global development challenges, including poverty, inequality, climate change, food security, health and education. Water, sanitation and hygiene (WaSH) improvements are indeed at the core of sustainable development and the overarching goal of poverty eradication, and are closely linked to the achievement of a number of internationally agreed development goals across the 2030 Agenda for Sustainable Development (UN Water, 2016a; United Nations General Assembly, 2015a).

According to recent statistics, however, universal access to safe drinking water and basic sanitation remains elusive in many countries: nearly one in every three people in the world do not have access to even a simple pit latrine, and one in ten have no access to a basic drinking water service, that is, an improved source within 30 minutes' round trip

Ricard Giné-Garriga is at Stockholm International Water Institute, Stockholm, Sweden. E-mail: ricard.gine@siwi.org

Agustí Pérez-Foguet is at Department of Civil and Environmental Engineering (DECA), Engineering Sciences and Global Development (Esc\&GD), Barcelona School of Civil Engineering, Universitat Politècnica de Catalunya, Barcelona, Spain. E-mail: agusti.perez@upc.edu to collect water (Joint Monitoring Programme, 2017). In addition, progress in reducing the gap between the poor and the well-off has not been sufficient in many countries. The equitable and sustainable provision of these essential services emerges as a top priority in the development arena, and the 2030 Agenda includes a dedicated Sustainable Development Goal on water and sanitation (SDG 6) to "ensure availability and sustainable management of water and sanitation for all" (United Nations General Assembly, 2015a). Targets 6.1 and 6.2 build on the Millennium Development Goals (MDGs) targets on drinking water and sanitation, and respond directly to the human right to safe drinking water and sanitation. The SDGs universally apply to all countries, thus governmental and nongovernmental organizations from both developed and developing countries will mobilize efforts to end water-related poverty. The pledge that "no one will be left behind" requires a focus on the poorest and most vulnerable people. Today, equitable access to safe drinking water and basic sanitation is a remote goal not only in rural communities and small towns, but also in cities and large metropolitan areas (de Albuquerque and Roaf, 2014; Joint Monitoring Programme, 2017; The World Bank, 2017a; World Health Organization, 2017).

The search for improved measures to target the neediest has captured the attention of researchers and policymakers 


\section{Monitoring and Targeting the Sanitation Poor: A Multidimensional}

\section{Approach}

3

\section{Abstract}

5 Water, sanitation and hygiene (WaSH) are at the core of sustainable development. As we embark on a 6 new round of global goals, namely the Sustainable Development Goals, a top priority is to address a 7 coherent framework for monitoring these services. In the coming years, the sector will witness the 8 development of a variety of multidimensional monitoring measures, albeit from different perspectives. 9 This paper discusses the adequacy and applicability of one approach that is increasingly adopted for 10 multidimensional poverty measurement at the household level, the Alkire-Foster methodology. 11 Drawing on this method, we identify and combine a set of direct household-related water and sanitation 12 deprivations that a person experiences at the same time. This new multidimensional measure is useful 13 for gaining a better understanding of the context in which WaSH services are delivered. It captures 14 both the incidence and intensity of WaSH poverty, and provides a new tool to support monitoring and 15 reporting, as well as targeting and planning. For illustrative purposes, one small town in Mozambique 16 is selected as the initial case study.

18 Keywords: water and sanitation poverty; poverty measurement and reporting; multidimensional 19 poverty; Sustainable Development Goals 


\section{1. Introduction}

22 Improving water and sanitation service delivery for billions of people is central to addressing many of 23 today's global development challenges, including poverty, inequality, climate change, food security, 24 health and education. Water, sanitation and hygiene (WaSH) improvements are indeed at the core of 25 sustainable development and the overarching goal of poverty eradication, and are closely linked to the 26 achievement of a number of internationally agreed development goals across the 2030 Agenda for 27 Sustainable Development (UN Water, 2016a; United Nations General Assembly, 2015a).

28 According to recent statistics, however, universal access to safe drinking water and basic sanitation 29 remains elusive in many countries: nearly one in every three people in the world do not have access to even a simple pit latrine, and one in ten have no access to a basic drinking water service - that is, an improved source within 30 minutes' round trip to collect water (Joint Monitoring Programme, 2017). In addition, progress in reducing the gap between the poor and the well-off has not been sufficient in many countries. The equitable and sustainable provision of these essential services emerges as a top priority in the development arena, and the 2030 Agenda includes a dedicated Sustainable Development Goal on water and sanitation (SDG 6) to "ensure availability and sustainable management of water and sanitation for all" (United Nations General Assembly, 2015a). Targets 6.1 and 6.2 build on the Millennium Development Goals (MDGs) targets on drinking water and sanitation, and respond directly to the human right to safe drinking water and sanitation. The SDGs universally apply to all countries, and governmental and nongovernmental organizations from both developed and developing countries will mobilize efforts to end water-related poverty. The pledge that 'no one will be left behind' requires a focus on the poorest and most vulnerable people. Today, equitable access to safe drinking water and basic sanitation is a remote goal not only in rural communities and small towns but also in cities and large metropolitan areas (de Albuquerque and Roaf, 2014; Joint Monitoring Programme, 2017; The World Bank, 2017a; World Health Organization, 2017). 
The search for improved measures to target the neediest has captured the attention of researchers and policymakers alike (Alkire and Foster, 2011; Grimm et al., 2008; Hicks, 1997; Ravallion, 2011; The World Bank, 2017b). A key direction for research has been the development of a coherent framework for measuring multidimensional poverty. Since the pioneering works of Bourguignon and Chakravarty (2003) and Tsui (2002), a number of approaches have been proposed to measure or analyse deprivation in multiple dimensions (Alkire and Foster, 2011; Ferreira and Lugo, 2013; Filmer and Pritchett, 2001; Houweling et al., 2003; Nussbaumer et al., 2012; Pachauri and Spreng, 2011). One illustrative example is the Multidimensional Poverty Index (MPI), which measures a set of 10 deprivations across three key dimensions: health, education and standard of living (Alkire and Santos, 2014). Some of these efforts have focused on assessing the delivery of WaSH services in rural contexts (Baum et al., 2013; Flores Baquero et al., 2013; Giné-Garriga and Pérez-Foguet, 2013, 2011; Luh et al., 2013; Sullivan et al., 2003). However, there is no consensus on how best to measure WaSH-related poverty across dimensions. Specifically, though it is widely accepted that there are complementary ways of profiling poverty and that each dimension should be accounted for in such an exercise, the literature shows two significant challenges that discourage the empirical use of these conceptually attractive measures.

The first challenge involves how the basic input data are combined (Giné-Garriga and Pérez-Foguet, 2010; Nardo et al., 2005). For new dimensions to provide significant additional information, they should not be strongly correlated with the rest. This would imply that there are no synergies or conflicts among them, which appears to be quite an unrealistic assumption (Munda and Nardo, 2005a; Nardo et al., 2005). If dimensional independence is assumed, then it may be meaningful to either aggregate dimensions or define a welfare function over multiple dimensions. Another related issue is the choice of weights to reflect the relative importance given to the various dimensions. A conventional practice is the selection of weights following consultation with experts (Flores Baquero et al., 2017; GallegoAyala and Juízo, 2014; Gómez-Limón and Sanchez-Fernandez, 2010), but they are often singled out for their arbitrariness (Booysen, 2002; Seth and McGillivray, 2018). Alternatively, multivariate 
techniques present an empirical and more objective option (Njong and Ningaye, 2008). However, statistical weights do not always reflect the priorities of decision-makers (Nardo et al., 2005), and they are data-specific. No weighting system is above criticism (Permanyer, 2011). As Anand and Sen argue:

"Since any choice of weights should be open to questioning and debating in public discussions, it is crucial that the judgements that are implicit in such weighting be made as clear and comprehensible as possible and thus be open to public scrutiny" (Anand and Sen, 1997). There are also many aggregating techniques available for constructing a composite. In linear aggregation rules, compensability among parts is implicit (Munda, 2012; Munda and Nardo, 2005a; Nardo et al., 2005), this implies complete substitutability among the various components considered. For example, in a water poverty index, water resources availability would compensate a loss of water quality. In poverty measures, a complete compensability may not be desirable as different dimensions - e.g. health, education or living standards - are equally legitimate. A non-compensatory logic might be necessary: multi-criteria analysis entails full non-compensability, and the use of a geometric aggregation emerges as an in-between solution (Giné-Garriga and Pérez-Foguet, 2010).

The second challenge relates to the method of identifying the poor. The conventional approach is through 'direct' measures of living standards, such as household income or expenditure, but in lowincome settings these data are often unreliable, unavailable or expensive and difficult to collect (Filmer and Pritchett, 2001). Therefore, there might be considerable uncertainty in monetary poverty estimates and figures (The World Bank, 2017b). In addition, the recognition that nonmonetary deprivations should be integrated in global poverty monitoring reinforces the need of extending the scope of monetary poverty measures with complementary nonmonetary measures (Alkire, 2018; Ferreira and Lugo, 2013; The World Bank, 2017b). The SDGs, for instance, focuses on poverty in all its many forms and dimensions, recognises that these are interlinked, and, accordingly, that policies to combat multidimensional poverty must also be integrated and multi-sectoral (United Nations General Assembly, 2015a). In an attempt to shift towards developing nonmonetary measures of poverty, Alkire 
and Foster introduced an intuitive approach for identifying the poor at the person / household level, namely the $M_{0}$ or Adjusted Headcount Ratio (Alkire et al., 2011; Alkire and Foster, 2007). The identification step employs two forms of cutoff: one within each dimension to determine whether a person is deprived in that dimension and a second across dimensions that identifies the poor by 'counting' the dimensions in which a person is deprived. In doing so, it gives clear priority to those suffering multiple deprivations and shows at a glance the incidence and the intensity of poverty. There are four properties of this methodology that have helped make it useful in practice (Alkire and Foster, 2016, 2011; Alkire and Santos, 2014) while extending the scope of application to various povertyrelated sectors (Alkire and Santos, 2010; Nussbaumer et al., 2012; Victor et al., 2014). First, $M_{0}$ is robust when using ordinal or cardinal variables as it classifies individuals' assets into 'deprived' and 'non-deprived'. Second, by adjusting the incidence of multidimensional poverty by the intensity, the measure satisfies the condition of dimensional monotonicity (Alkire and Foster, 2011): if an additional person becomes poor or if a person already considered as multidimensionally poor becomes poor in additional dimension(s), $M_{0}$ will increase. Third, the measure is decomposable by population subgroups, meaning that the $M_{0}$ of the overall society can be obtained as the population-weighted sum of subgroup poverty levels (subgroups need to be mutually exclusive and collectively exhaustive of the population). Subgroup decomposability enables poverty comparisons across subgroups, facilitating regional analysis and targeting. Fourth, after identification, $M_{0}$ can be broken down by indicator. The overall $M_{0}$ can be expressed as the weighted sum of the proportion of the total population who have been identified as poor and are deprived in each indicator (weights referring to the relative weight of each indicator). Analogous to population subgroup decomposability, dimensional breakdown enables an analysis of the contribution of each indicator to overall poverty.

The Alkire-Foster approach has been subject to criticism. One definitional concern relates to the unit of study, as different units may apply to different dimensions (The World Bank, 2017b). Does the analysis focus on the whole household (for example, the household has not a latrine), on everyone in 
the household (e.g. no one has primary education), or on a specified person within the household (e.g. the respondent or the head of household)? A related definitional issue concerns the reference population. The majority of the indicators - such as those for access to safe drinking water - apply to the whole population, while there are some indicators that only apply to a subset of the population for example, in the case of the education domain, various indicators apply only where there are schoolage children in the household (The World Bank, 2017b). Another constraint is that sometimes deprivations overlap (Alkire, 2018), and the poor often experience a multiplicity of overlapping deprivations: do those with low levels of education also suffer from poor health? There is correlation and interdependence between different deprivations, which are seldom stated explicitly and scrutinized by public debate (The World Bank, 2017b). The manner in which information on deprivation is aggregated across dimensions is also questioned. Arbitrary weights are often adopted, usually in the form of equal weights (Ferreira and Lugo, 2013). And because they employ linear aggregation techniques, weights have the meaning of trade-off (substitution) ratios between the constituent components of welfare: a certain extra amount of one component (e.g. nutrition) will exactly offset the change in another component (e.g. schooling) to leave the index unchanged (Munda and Nardo, 2005b; Ravallion, 2011).

However, international institutions and poverty experts have shifted towards recognizing the importance of developing indicators related to the nonmonetary dimensions of poverty, and the monitoring and reporting architecture at the international level is rapidly evolving to integrate this multidimensional perspective, thus improving the identification of high-risk groups (Joint Monitoring Programme, 2017, 2015, 2012; United Nations, 2013). Two examples illustrate some of the recent changes in this direction: 1) the new set of indicators proposed by the WHO / UNICEF Joint Monitoring Programme (JMP) and the UN Water Global Analysis and Assessment of Sanitation and Drinking-Water (GLAAS), as discussed elsewhere in the literature (Flores Baquero et al., 2015; GinéGarriga et al., 2017; Jiménez et al., 2018) and 2) the global goal for water proposed for the SDG era 
145 (UN Water, 2016b; United Nations General Assembly, 2015a). It can be seen, for instance, that the indicator employed by the JMP to monitor SDG Target 6.1 on drinking-water builds on the concept of "safely managed drinking water service", which is based on three criteria or dimensions: accessibility - an improved water source should be accessible on premises, availability - water should be available when needed, and safety - the water supplied should be free from contamination (Joint Monitoring Programme, 2017).

In order to contribute further to the ongoing debate about improved monitoring and reporting methods, the purpose of this study is to adapt the Alkire-Foster methodology for the multidimensional measurement of poverty related to the delivery of water and sanitation services. A new monitoring and reporting measure is first proposed by combining a set of direct household-related water and sanitation deprivations. Second, the question relates to how this measure can contribute to shape action. Different applications are discussed to demonstrate the likely utility and the policy relevance of this multidimensional tool. A case study from a small town in Mozambique has been selected for illustrative purposes. The rest of this paper is organised into three sections. Following this introductory section, Section 2 describes the methods of this study and documents the methodological background of the Alkire-Foster approach. Section 3 discusses the results achieved. It first shows to what extent the proposed measure is able to produce a consistent, credible and complete picture of the context in which sanitation services are delivered. Second, it applies three robustness tests to assess comparisons as poverty cutoffs and other parameters change. The paper ends in Section 4 with a synthesis of conclusions and recommendations.

\section{Methods}

This section discusses the methodological foundations of the study and provides guidance for operationalizing the concept of WaSH poverty through an adaptation of the Adjusted Headcount Ratio. It seeks to describe the water and sanitation services delivered at the household level from a 
multidimensional perspective, i.e. it takes into account the different attributes that contribute to household poverty due to poor access to these basic services. For the sake of simplicity, however, this paper focuses on the issue of sanitation and hygiene for various reasons. Sanitation has a collective dimension, e.g. one person defecating in the open may compromise a clean and hygienic environment that benefits everyone. In addition, the sanitation MDG target was missed by almost 700 million people and the most recent official figures estimated that that about 2.3 billion people still use unimproved sanitation facilities (Joint Monitoring Programme, 2017). Finally, despite all this, sanitation has been relatively little studied in comparison with water.

The Municipality of Manhiça, which is located in the Manhiça District, Maputo Province, in southern Mozambique, has been selected as the initial case study. Administratively, the municipality has 18 inhabited bairros (neighbourhoods) and covers an area of roughly $250 \mathrm{~km}^{2}$. According to local estimates, there is a population of approximately 61,000 , living in peri-urban and rural contexts. In 2012, a household-based survey was conducted to identify deprivations in WaSH services at the dwelling. The design and selection of the sample draw on the Multiple Indicator Cluster Survey (MICS), i.e. a methodology developed by UNICEF to collect social data (United Nations Children's Fund, 2006), and is is presented in detail in a previous article (Giné-Garriga et al., 2013). In all, 1,229 households were surveyed to allow for separate estimates for each of the targeted bairros. In every visited household, the service level was captured through a structured questionnaire administered to primary caregivers and by direct observation. The complete set of data used in this study is available at https://doi.org/10.5281/zenodo.1490900.

\subsection{Sanitation and hygiene poverty: defining the scope}

The multidimensional nature of sanitation poverty should be reflected in the choice and structure of the variables. In turn, variables should be selected on the basis of their relevance to the issue at hand and measurability, i.e. availability of sufficient and reliable data. At the international level, there is 
195 broad consensus that sanitation monitoring should take into account the normative criteria enshrined 196 in the UN resolution on Human Rights to Water and Sanitation (Giné-Garriga et al., 2017; Joint 197 Monitoring Programme, 2015). In keeping with this goal, the quality of sanitation services may be

described on the basis of the contents of the Human Right to Sanitation (HRtS) resolution (United Nations, 2015, 2010a, 2010b). We adopt this approach herein, and each normative criterion of the HRtS is understood as a 'poverty' dimension. Indicators are consequently classified in five different categories - availability, physical accessibility, quality and safety, affordability and acceptability (each category is directly related to a human rights normative criterion). Table 1 proposes a short list of illustrative indicators that could be employed to monitor sanitation outcomes in households from a human rights perspective. Each indicator is assessed against four different levels of service, namely good service level, intermediate, poor and no level of service (Giné-Garriga et al., 2017). By way of example, people who defecate openly in gutters, fields, beaches and water bodies, presenting significant risks to personal security and public health, suffer the lowest level of service (i.e. no service) in relation to all five categories. 
20able 1 Sanitation descriptors based on human right normative content: dimensions, indicators, service levels and scores / deprivation cut-offs (Giné-Garriga et al., 2017)

\begin{tabular}{|c|c|c|c|c|c|c|}
\hline \multirow{2}{*}{$\begin{array}{l}\text { Normative } \\
\text { Criteria of } \\
\text { the HRtS }\end{array}$} & \multirow{2}{*}{ Indicator } & \multirow{2}{*}{$\begin{array}{l}\text { Survey } \\
\text { Technique }\end{array}$} & \multicolumn{4}{|c|}{ Service Level Description } \\
\hline & & & Good level of service & Intermediate & Poor & No level of service \\
\hline \multirow{2}{*}{ Availability } & $\begin{array}{l}\text { Type of sanitation facility - Sanitation } \\
\text { ladder }\end{array}$ & $\begin{array}{l}\text { Direct question / } \\
\text { Observation }\end{array}$ & Improved a $^{\text {a }}$ & Improved / Shared & Unimproved a & Open Defecation \\
\hline & Toilet facility location & $\begin{array}{l}\text { Direct question / } \\
\text { Observation }\end{array}$ & Inside the house & In the compound & $\begin{array}{l}\text { In the neighbour's compound } \\
\text { / In a public place }\end{array}$ & \\
\hline \multirow{4}{*}{$\begin{array}{l}\text { Physical } \\
\text { Accessibility }\end{array}$} & $\begin{array}{l}\text { Safety and security while accessing the } \\
\text { sanitation facility }\end{array}$ & $\begin{array}{l}\text { Direct question } \\
\text { (perception) }\end{array}$ & $\begin{array}{l}\text { Safe and secure (the physical } \\
\text { integrity of users while } \\
\text { accessing the facility is } \\
\text { guaranteed) }\end{array}$ & & $\begin{array}{l}\text { Unsecure (the physical } \\
\text { integrity of users while } \\
\text { accessing the facility is not } \\
\text { guaranteed) }\end{array}$ & \\
\hline & $\begin{array}{l}\text { Safety and security while using the } \\
\text { sanitation facility }{ }^{b}\end{array}$ & $\begin{array}{l}\text { Direct question } \\
\text { (perception) }\end{array}$ & $\begin{array}{l}\text { Safe and secure (the physical } \\
\text { integrity of users while using } \\
\text { the facility is guaranteed) }\end{array}$ & & $\begin{array}{l}\text { Unsecure (the physical } \\
\text { integrity of users while using } \\
\text { the facility is not guaranteed) }\end{array}$ & \\
\hline & Continuity of use of the latrine & Direct question & $\begin{array}{l}\text { Full access (all day and } \\
\text { night) }\end{array}$ & $\begin{array}{l}\text { Partial access (the facility } \\
\text { is available at least } 18 \\
\text { hours per day) }\end{array}$ & $\begin{array}{c}\text { Limited access (the facility is } \\
\text { available less than } 18 \text { hours } \\
\text { per day) }\end{array}$ & \\
\hline & Suitability of use of the latrine ${ }^{c}$ & Observation & $\begin{array}{l}\text { Suitable for all (men, women, } \\
\text { girls and boys of all ages) }\end{array}$ & & $\begin{array}{l}\text { Not suitable for particular } \\
\text { population groups (the } \\
\text { elderly, women, girls or boys } \\
\text { of all ages, etc.) }\end{array}$ & \\
\hline $\begin{array}{l}\text { Quality and } \\
\text { Safety }\end{array}$ & $\begin{array}{l}\text { Sanitary conditions of the latrine } \\
\text { (presence of insects, unpleasant smell, } \\
\text { cleanliness) }{ }^{c}\end{array}$ & Observation & $\begin{array}{l}\text { Adequate sanitary conditions } \\
\text { (no insects, no smell, } \\
\text { adequately clean) }\end{array}$ & $\begin{array}{c}\text { Acceptable sanitary } \\
\text { conditions (few insects, } \\
\text { slight unpleasant smell, } \\
\text { some dirt but no faeces or } \\
\text { urine) }\end{array}$ & $\begin{array}{l}\text { Poor sanitary conditions } \\
\text { (insects, strong unpleasant } \\
\text { smell, faeces or urine on the } \\
\text { floor) }\end{array}$ & \\
\hline
\end{tabular}




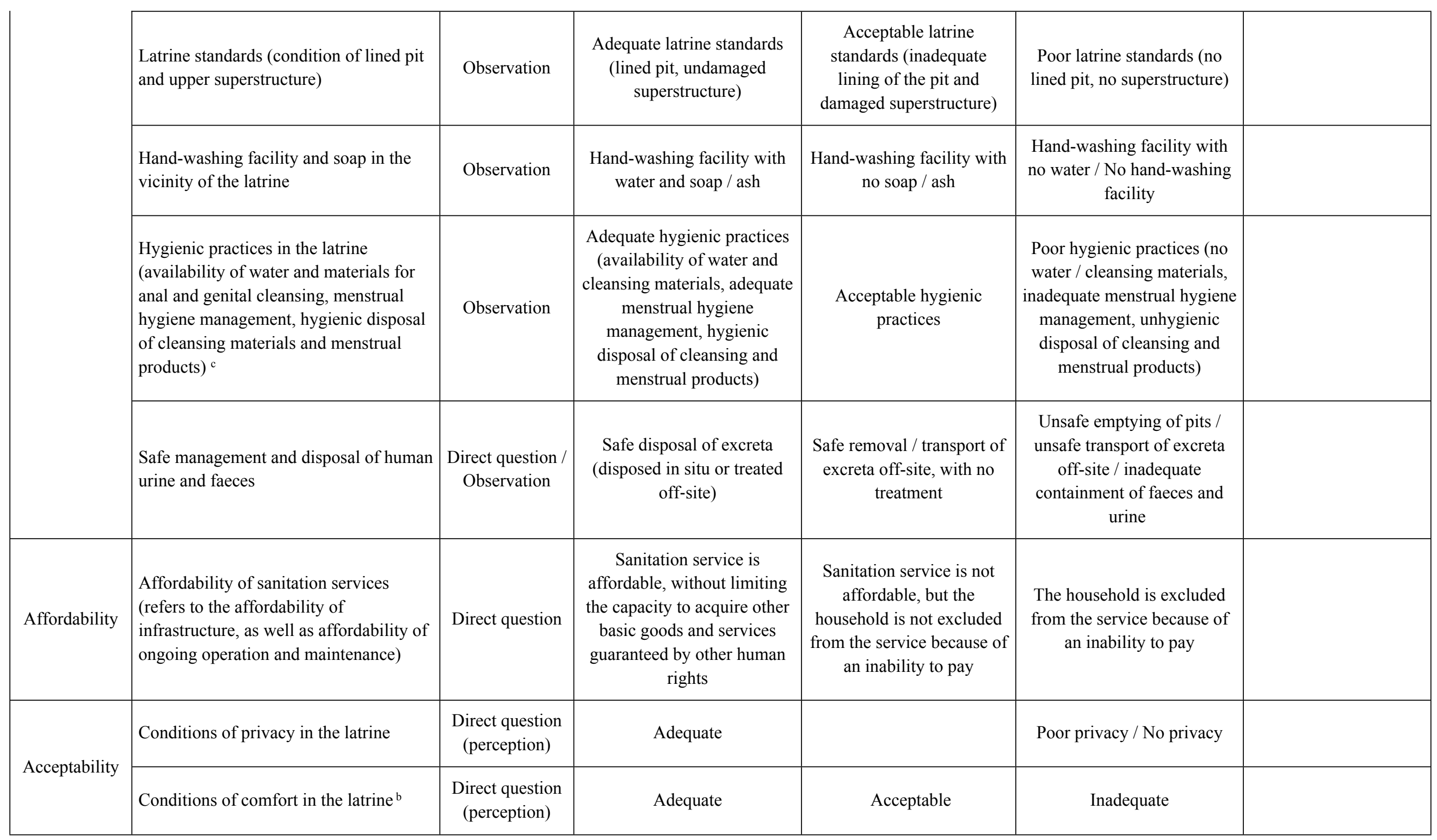




\begin{tabular}{|l|l|l|c|c|c|}
\hline & Cultural issues $^{\mathrm{b}}$ & Direct question & $\begin{array}{c}\text { The facility is culturally } \\
\text { acceptable to all household } \\
\text { members }\end{array}$ & $\begin{array}{c}\text { Cultural issues hinder } \\
\text { continued use of the latrine } \\
\text { by at least one member of } \\
\text { the household }\end{array}$ & $\begin{array}{c}\text { Cultural issues hinder } \\
\text { continued use of the latrine } \\
\text { by all household members }\end{array}$ \\
\hline
\end{tabular}

Notes: a) An improved sanitation facility is defined as one that hygienically separates human excreta from human contact. It includes the following types: flush or pour flush toilets to sewer systems, septic tanks or pit latrines, ventilated improved pit latrines, pit latrines with a slab, and composting toilets. Unimproved sanitation facilities include flush/pour flush not going to sewer/septic/pit, pit latrines without a slab, hanging and bucket latrine; b) Indicator removed from the dataset due to poor data quality; c) The need to adapt toilet facilities would not apply to households where disabled people are known not to reside; c) The proposed aggregation function employed to build up the composite is the arithmetic mean of available indicators (e.g. to calculate an index of latrine sanitary conditions, one could average three proxies, namely inside cleanliness, presence of insects and smell).

Source: Giné-Garriga et al., 2017 


\section{$212 \quad$ 2.2. Identifying the sanitation poor}

213 To develop a method to target multidimensional sanitation poverty at the household level, we review

214 the relevant literature, notably from the Oxford Poverty and Human Development Initiative (OPHI) (Alkire and Foster, 2011, 2007; Alkire and Santos, 2010; Njong and Ningaye, 2008; Santos et al., 2015). We captured a set of sanitation and hygiene deprivations that may affect a household. The new measure encompasses in five dimensions the normative content of human rights obligations related to sanitation - each dimension representing one normative criterion (see Table 1). A household is identified as sanitation poor if the combination of the deprivations faced exceeds a pre-defined threshold. The Adjusted Headcount Ratio (or $M_{0}$ ) is the product of a headcount ratio (share of people identified as sanitation poor) and the average intensity of deprivation of the sanitation poor. Consequently, $M_{0}$ assesses the nature and intensity of poverty at the individual level by considering overlapping deprivations suffered at the same time, with poor people being those who are multidimensionally poor (Alkire and Foster, 2011, 2007). The $M_{0}$ can be used as an analytical tool to identify the most vulnerable people, show the indicators in which they are deprived and the extent of their poverty, and help reveal the interconnections among deprivations. Application of this method is detailed elsewhere (Alkire and Foster, 2011; Alkire and Santos, 2010). Briefly, the steps for identification and aggregation of households include:

1. Defining the dimensions and corresponding set of indicators that will be considered in the multidimensional measure (Table 1). Data for all indicators need to be available for the same household; otherwise, either the household or the indicator is removed from the dataset (Alkire and Santos, 2014). Three indicators of Table 1 were for instance removed from the analysis due to poor data quality.

2. Determining the level of service for each dimension. By applying a conservative interpretation, it is assumed that the service level is given by the worst-performing indicator of each dimension. 
3. Setting the deprivation cutoff for each dimension, which is the level of achievement considered sufficient in order to be non-deprived in each dimension.

4. Applying the cutoff to identify whether each household is deprived or not in each dimension.

5. Selecting the weights for the contribution of each dimension to the overall measure, such that these sum to one (equal weights among dimensions are assumed for simplicity).

6. Counting the number of deprivations for each household, i.e. creating the weighted proportion of deprivations for each household. This can be called its deprivation score.

7. Determining the poverty lines (poverty cutoff ' $k$ '), namely the proportion of weighted deprivations a household needs to experience in order to be considered multidimensionally poor. Obtaining the set of poor households ' $\mathrm{N}_{\mathrm{P}}$ ' by identifying each household as multidimensionally poor or not, according to the selected poverty cutoff. In practice, it is useful to calculate the measure for several values of $k$ and then perform robustness checks for the different cutoffs.

8. Computing the proportion of people who have been identified as multidimensionally poor in the population. This is the headcount ratio $H$, also called the incidence of multidimensional poverty.

9. Computing the average share of weighted indicators in which poor people are deprived. This entails adding up the deprivation scores of the poor and dividing them by the total number of poor people. This is the intensity of multidimensional poverty, $A$.

10. Computing the $M_{0}$ measure as the product of the two previous partial indices: $M_{0}=H \cdot A$. Analogously, $M_{0}$ can be obtained as the sum of the weighted deprivations that the poor (and only the poor) experience, divided by the total population.

One clear advantage of this methodology is that it captures both the incidence (number of sanitation poor people) as well as the intensity (how sanitation poor they are). Related to this, as previously mentioned, the method applied here to sanitation poverty respects the condition of dimensional 
monotonicity. That is, if an additional person becomes poor or if a person already considered as multidimensionally poor becomes poor in additional dimension(s), it is reflected in an increase in the aggregated value $M_{0}$. Another useful property is decomposability, which allows the index to be broken down by population subgroup (such as region, wealth or ethnicity) and by dimensions (dimensional breakdown). In doing so, it can help show the characteristics of multidimensional poverty for specific subgroups and the contributions of deprivations in each indicator to overall poverty, respectively.

\section{Results and Discussion}

The discussion below first seeks to determine how the proposed measure reveals sanitation-related deprivations and whether it is useful for identifying and targeting the sanitation poor. Second, it presents a number of robustness tests to assess comparisons as poverty cutoffs and other parameters changes.

\subsection{Targeting the sanitation poor}

In poverty measurement, there is a clear interest in understanding how a multidimensional poverty measure can be used to shape action, i.e. in discussing the policy relevance of this measure. The literature shows various good examples (e.g., Alkire, 2018), a few of these are discussed below.

To start with, the $M_{0}$ is computed at the municipality level by setting two deprivation cutoffs for all indicators - the 'intermediate service level' and 'good service level' - and various poverty cutoffs $\mathrm{k}$ (or, alternatively, the poverty line). The multidimensional headcount ratio $\mathrm{H}$ provides an insight into the incidence of poverty. Table 2 shows that $\mathrm{H}$ logically decreases with both the deprivation cutoff and the poverty cutoff $\mathrm{k}$. By way of example, when considering the deprivation cutoff 'intermediate service level', 57.4\% of the households in Manhiça would be identified as sanitation poor for a cutoff $\mathrm{k}$ equal to 0.6 (i.e. they would have a deprivation score equal or higher than 0.6). However, if the reference level of service is taken as 'good', then the percentage of poor amounts to $99.3 \%$. In a similar vein, the 
highest cutoff (which corresponds to simultaneous deprivations in 100\% of indicators) would identify $17.4 \%$ and $46 \%$ of households as poor (depending on the deprivation cutoff), whereas the lowest cutoff $(\mathrm{k}=0.2)$ would identify $96.5 \%$ and $100 \%$ of households as poor, respectively. One may be also interested in knowing how sanitation poor the poor are or the intensity of multidimensional poverty (A). For example, when $\mathrm{k}=0.6$, poor people are deprived, on average, in $75 \%$ and $87.3 \%$ of the dimensions. The headcount ratio $\mathrm{H}$, i.e. the proportion of people considered as sanitation poor, is easily understood by policy-makers, as it has the advantage of transparency and intuition (Alkire, 2018). However, it does not satisfy the dimensional monotonicity property. This limitation, as previously mentioned, is overcome by the Adjusted Headcount Ratio $M_{0}$. In terms of policy formulation, it might be stated that increasing the poverty cutoff hinders the definition of poverty alleviation measures and the line between the poor and the non-poor is not easy to interpret for low deprivation scores $(\mathrm{k} \leq 0.4)$.

Table 2 Adjusted Headcount Ratio Adapted to Sanitation in Manhiça, Mozambique, for Two Deprivation Cutoffs and Five Poverty Cutoffs $k$

\begin{tabular}{lcccccccccc}
\hline & \multicolumn{3}{c}{ Intermediate Service Level } & \multicolumn{5}{c}{ Good Service Level } \\
\cline { 2 - 11 } & $\boldsymbol{k}=\mathbf{0 . 2}$ & $\boldsymbol{k}=\mathbf{0 . 4}$ & $\boldsymbol{k}=\mathbf{0 . 6}$ & $\boldsymbol{k}=\mathbf{0 . 8}$ & $\boldsymbol{k}=\mathbf{1}$ & $\boldsymbol{k}=\mathbf{0 . 2}$ & $\boldsymbol{k}=\mathbf{0 . 4}$ & $\boldsymbol{k}=\mathbf{0 . 6}$ & $\boldsymbol{k}=\mathbf{0 . 8}$ & $\boldsymbol{k}=\mathbf{1}$ \\
\hline$H$ & 0.965 & 0.876 & 0.574 & 0.256 & 0.174 & 1 & 1 & 0.993 & 0.895 & 0.460 \\
$A$ & 0.590 & 0.629 & 0.750 & 0.936 & 1.000 & 0.870 & 0.870 & 0.873 & 0.903 & 1.000 \\
$M_{0}$ & 0.569 & 0.551 & 0.430 & 0.240 & 0.174 & 0.870 & 0.870 & 0.867 & 0.808 & 0.460 \\
\hline
\end{tabular}

Note: k: Poverty cutoff; $\mathrm{M}_{0}$ : Adjusted Headcount Ratio; $\mathrm{H}$ : Headcount ratio (incidence of multidimensional poverty); A: Multidimensional intensity of poverty

Alternatively, it might be interesting to analyse the composition of multidimensional poverty by examining the percentage contribution of each dimension to overall poverty. This composition breaks poverty down into its different dimensions, so that the total of the percentages sum to $100 \%$. It can be seen in Figure 1 that the poor in Manhiça exhibit the highest deprivation levels in quality and safety of sanitation facilities, followed by the availability of infrastructure. Therefore, a dimensional breakdown of poverty reveals different underlying structures of poverty, which in turn suggests different policy responses. In Manhiça, for instance, policy attention should be primarily directed towards improving 
308 the quality of latrines - e.g. by reviewing the construction standards of toilets and/or by providing a 309 basic handwashing facility in or near sanitation infrastructure - and eliminating open defecation.

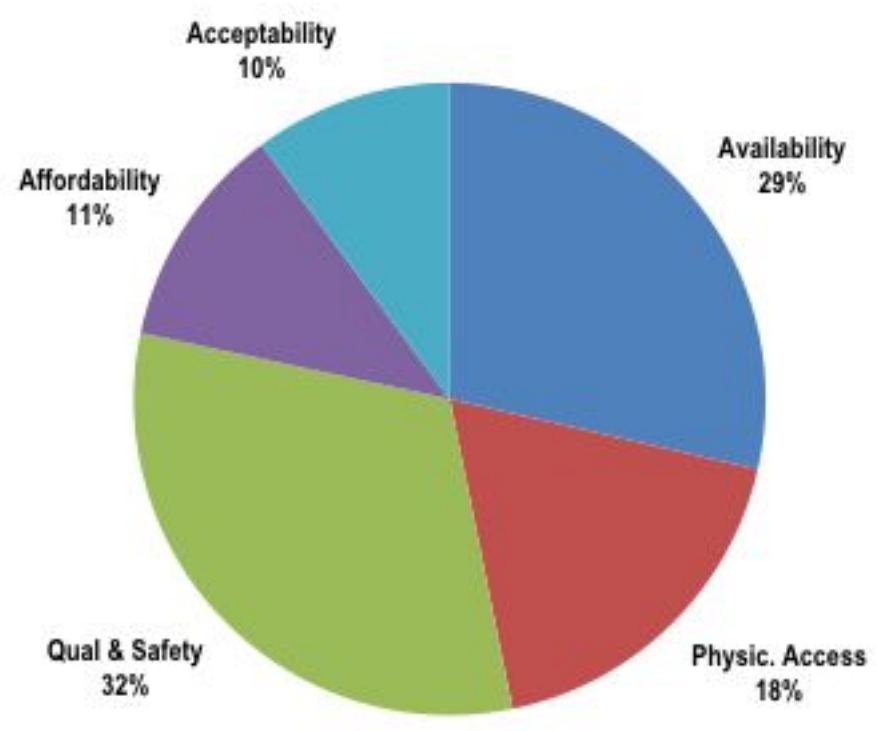

Figure 1 Broken Down by Dimension of Multidimensional Poverty for an 'Intermediate Level of Service' and $k=0.4$, in Manhiça

Another virtue of the measure is, as previously outlined, decomposability by population subgroups.

This allows changes over time to be reported across these groups, making visible whether the poorest are enjoying the fastest progress in sanitation poverty reduction or whether their progress is slower than less poor groups. For instance, the multidimensional poverty measure can be decomposed based on wealth categories. Showcasing the example of Manhiça, Figure 2 indicates that the poverty stratification is consistent with poor levels of sanitation services. Remarkably, the sanitation gap between the richest and the rich is larger than the sanitation gap between the rich and the poorest, which suggests that affordability is probably the main obstacle to access a decent sanitation facility. 


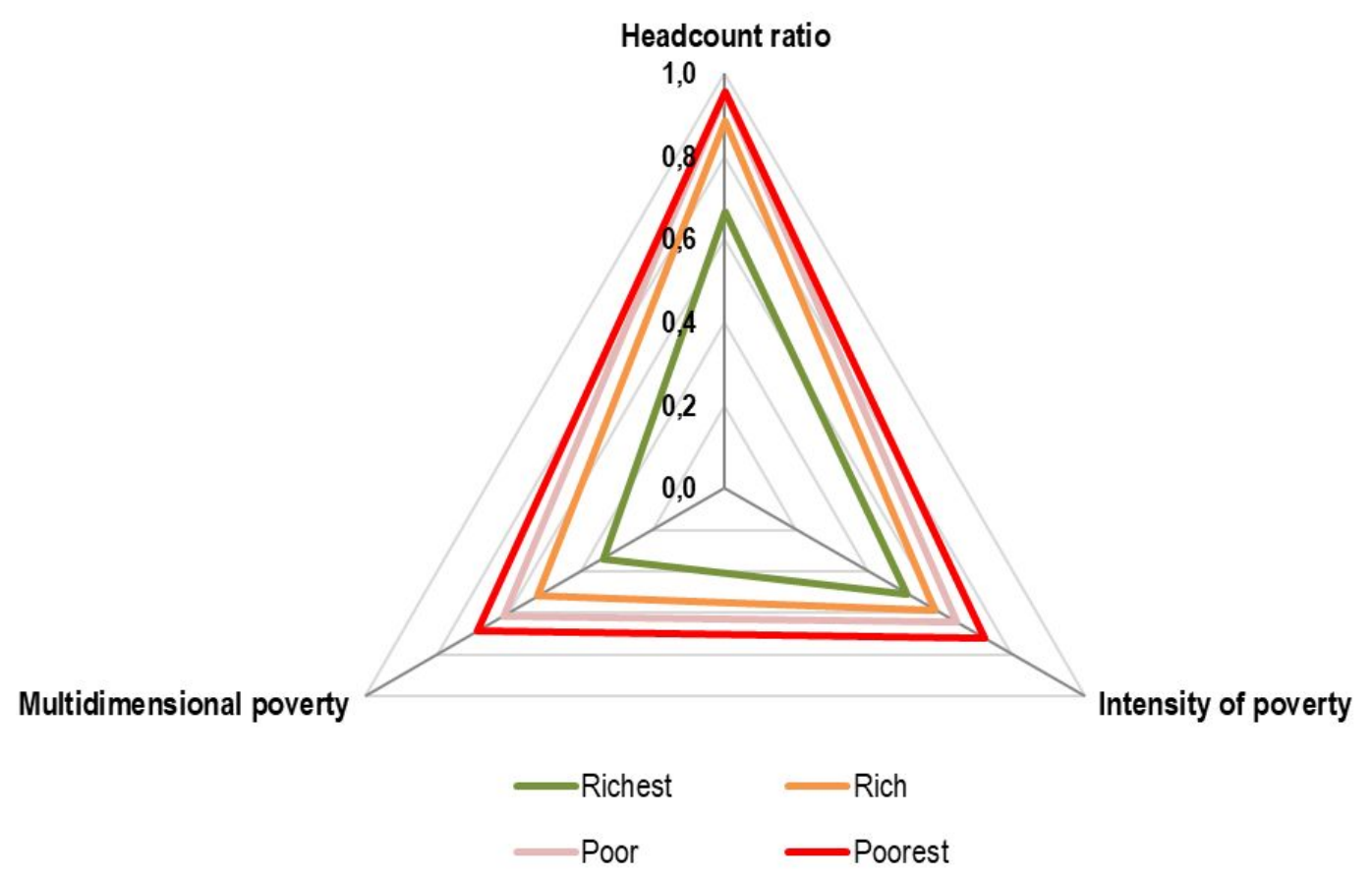

Figure 2 Multidimensional poverty $\left(M_{0}\right)$ by Wealth Index in Manhiça

Poverty can also be broken down by regions or other administrative divisions. This disaggregation brings out internal contrasts and shows who is poorest. It allows directing efforts to the neediest regions and to shape both sectoral and regional budget allocation. In Figure 3, the $M_{0}$ has been computed for all bairros in Manhiça for which appropriate data are available. To illustrate, the poverty cutoff $\mathrm{k}$ has been set at 0.4 , which implies that a household is considered as poor if it does not fulfil two or more rights' normative criteria. The bairros are classified according to the degree of poverty, ranging from acute poverty $\left(M_{0}>0.65\right.$; e.g. Ribjene $)$ to moderate poverty $\left(0.45<M_{0}<0.55\right.$; e.g. Cambeve $)$ or low poverty $\left(M_{0}<0.35\right.$; Manhiça Sede). The details on the results for the headcount ratio, intensity of poverty and $M_{0}$ are available in Annex A. As complementary information, we also report on individual indicators, such as the coverage of basic sanitation or the prevalence of open defecation. These are the standard indicators typically employed to globally report the sanitation data at the national level (Joint Monitoring Programme, 2017). 


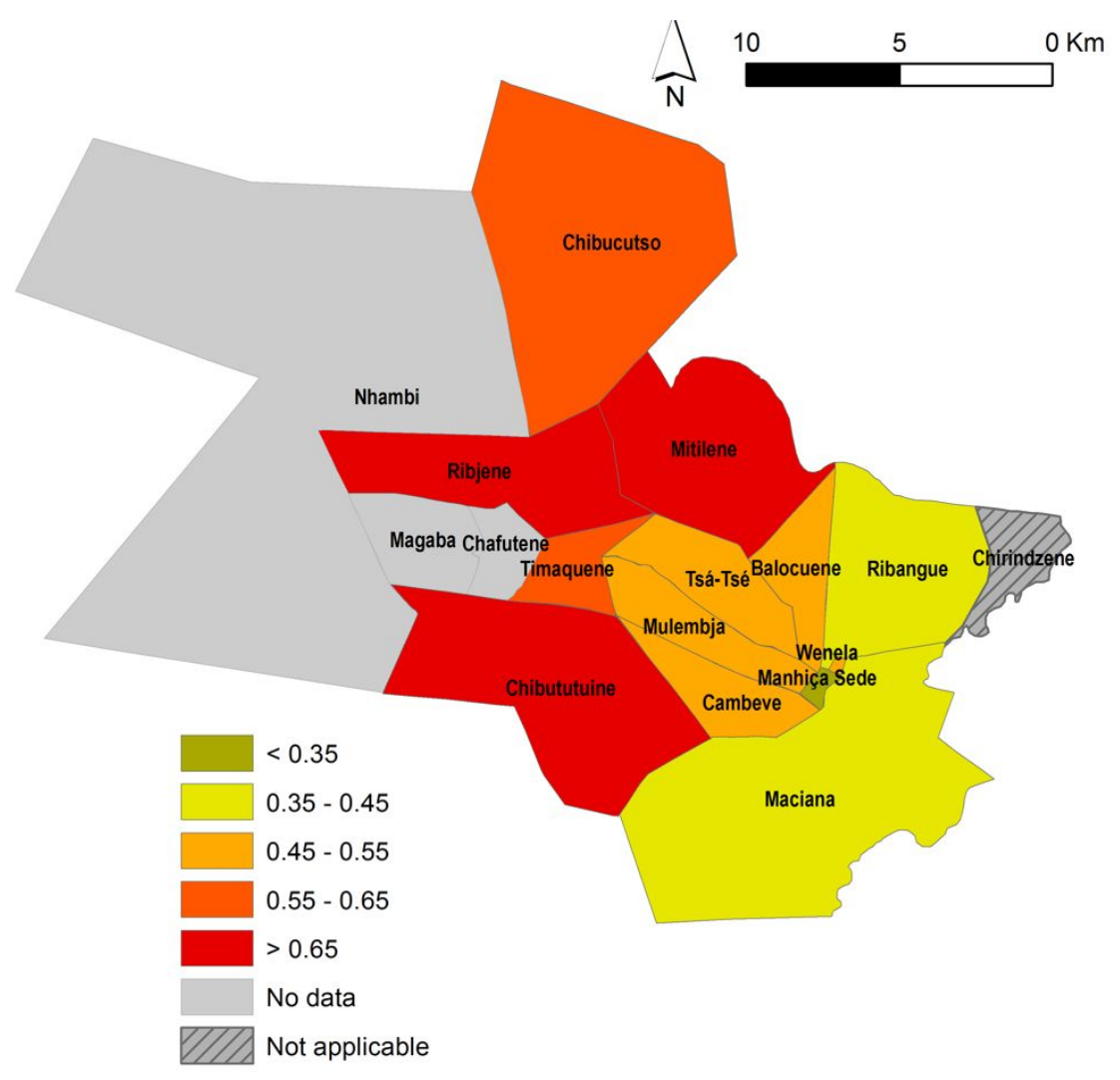

Figure $3 M_{0}$ at Bairro Level, Manhiça

The use of different indicators illustrates another merit: the complementarity of a multidimensional measures and standard sanitation indicators. Each measure informs about different dimensions of the service or draw attention to different groups of poor persons, which provides a more accurate understanding of sanitation poverty. For instance, the maps of Figures 4 and 5 confirm that the situation in the municipality of Manhiça is far from being adequate: use of improved infrastructure stands at $26.4 \%$, and $14.2 \%$ of total population has no access to sanitation at all. In addition, disparities exist by bairros, and e.g. population in Manhiça Sede (coverage of 58.7\%) is nine times as likely to use an improved sanitation facility as the population in Mitilene (6.7\%). On the other hand, a large majority of households defecate in the open in Ribjene (61.3\%), while in other bairros this practice has been almost eliminated. Different (but complementary) measures pointing to similar problems provide legitimacy and credibility to decision-making and promotes public confidence in the decision-makers. 


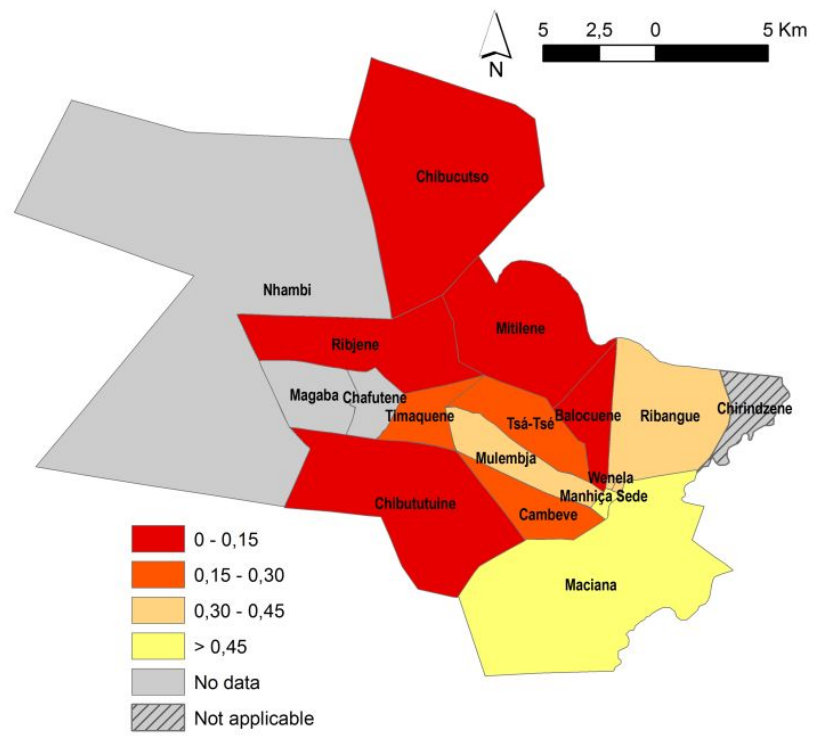

Figure 4 Improved Sanitation at Bairro Level, Manhiça

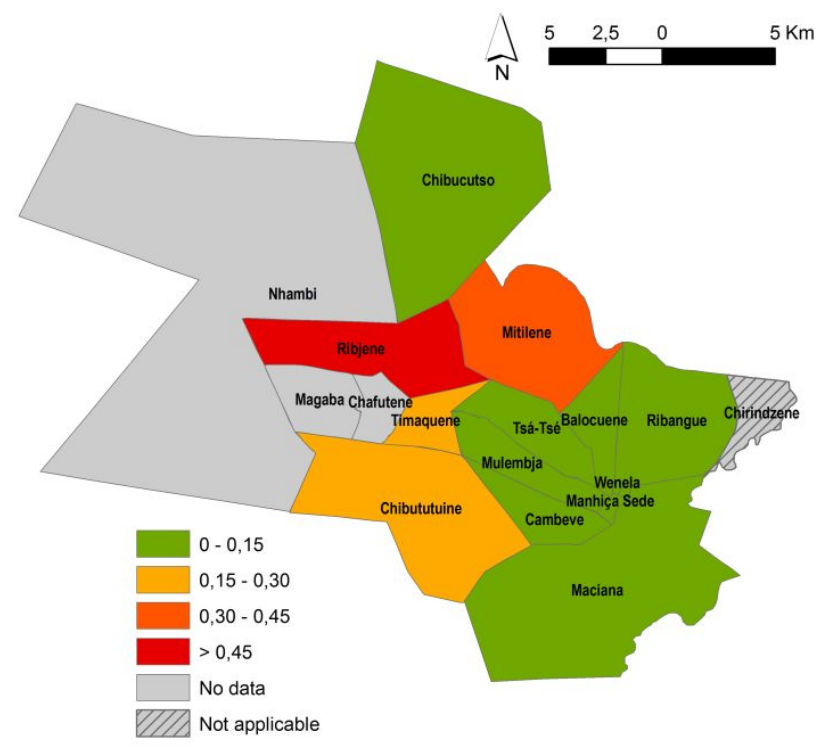

Figure 5 Open defecation at Bairro Level, Manhiça

Finally, Figure 4 plots the headcount ratio against the intensity of poverty. It shows that all bairros in Manhiça are below an imaginary trend line, i.e. the headcount ratio of the poor is significantly higher compared to the intensity of poverty. The plotted results are useful for identifying the poorest bairros from a dual perspective. For instance, the level of poverty in Ribjene $\left(M_{0}=0.838\right)$ is nearly three times higher than in Manhiça Sede $\left(M_{0}=0.333\right)$. Similarly, although the $M_{0}$ values of Timaquene and Balocuene are comparable ( 0.574 and 0.547 , respectively), the ratio of people experiencing sanitation poverty is higher in Balocuene. In contrast, the intensity of sanitation poverty is greater in Timaquene. Finally, the intensity of sanitation poverty is almost identical in Balocuene and Wenela. Nonetheless, they are poorer, in relative terms, in the former than in the latter. 


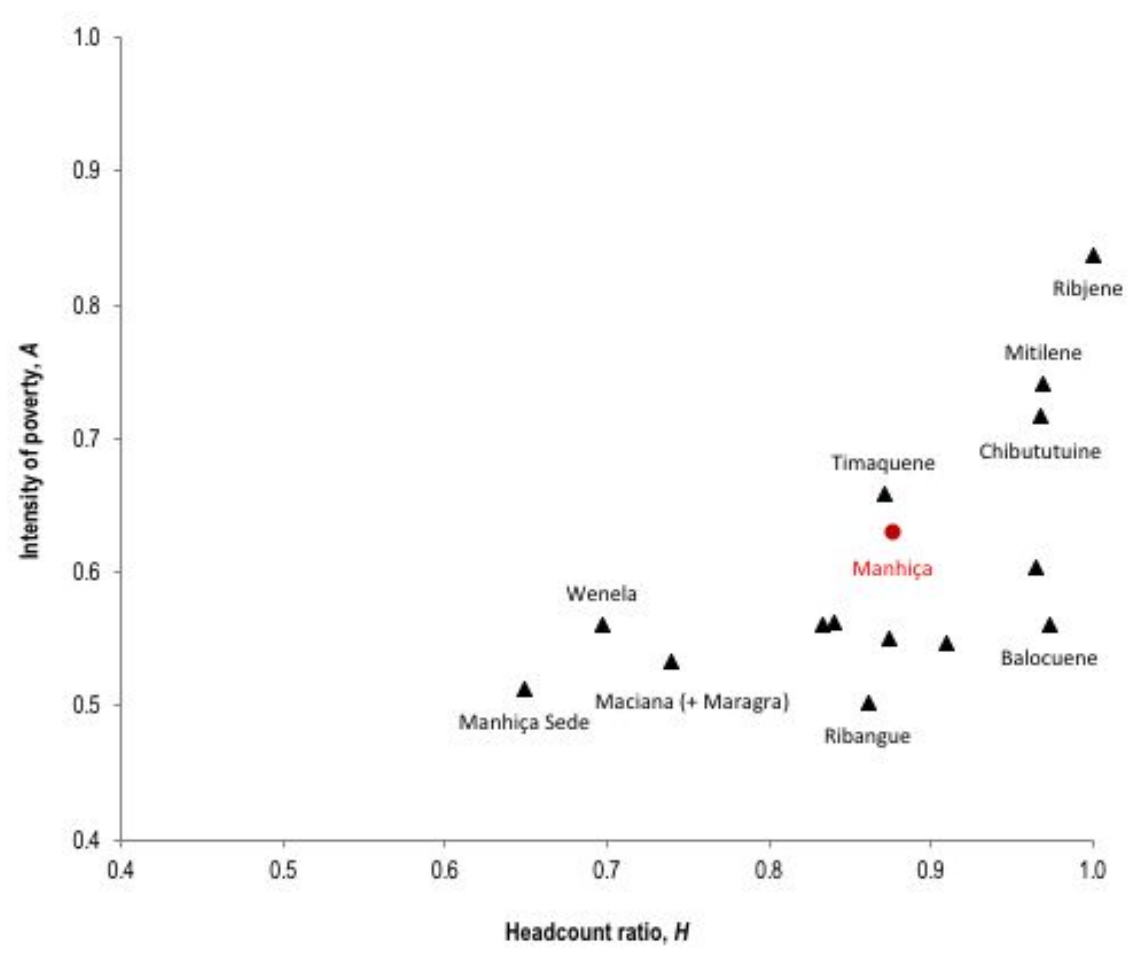

Figure 4 Headcount Ratio vs. Intensity of Sanitation Poverty at Bairro Level, Manhiça

In short, this first part of the discussion has sought to assess the policy relevance of a multidimensional measure to target the sanitation poor. With its disaggregation by group or region and breakdown by indicator, this measure can be used for planning purposes as part of the budget allocation formulae. Further, it can be used for targeting in two senses: targeting the poorest areas and also the weakest sanitation dimensions (e.g. availability of infrastructure, hygiene behaviour, affordability issues, etc.). Also, by comparing the proposed measure with the standard indicators employed by the international community to measure progress on sanitation (Joint Monitoring Programme, 2017), it has been shown that a multidimensional focus offers a complementary perspective,.

\subsection{Robustness analysis}

The design of a poverty measure involves the selection of a set of parameters. This raises the question of how conclusive policy prescriptions are subject to these parameter choices (Santos et al., 2015), i.e. how dependent are achieved results on the methodology employed and the assumptions made. 60379 Specifically, the construction of the proposed measure involves two stages where subjective judgement 
3380 is exercised: the choice of the indicators, constrained by the availability of data, as well as the selection of parameters within the aggregating model, such as the poverty cutoff, deprivation cutoffs or weights. With this in mind, the robustness of results to 'subjective' specifications of parameters can be analysed in several ways (Santos et al., 2015). Three different tests are carried out below by modifying two key parameters.

First, we vary the cutoff of multidimensional poverty, $k$, and evaluate the impact on the $M_{0}$. For this purpose, we rank the bairros based on the $M_{0}$ and consider the change in ranking when the cutoff is altered (between $0.2,0.4,0.6,0.8$ and 1). It is gleaned from Figure 7 that a change in the poverty cutoff does not lead to significant changes in the bairros' classifications. In fact, only four bairros (Manhiça Sede, Matadouro, Mulembja and Tsa-Tsé) change more than three positions in this analysis when the $k$ value is increased by 0.4 .

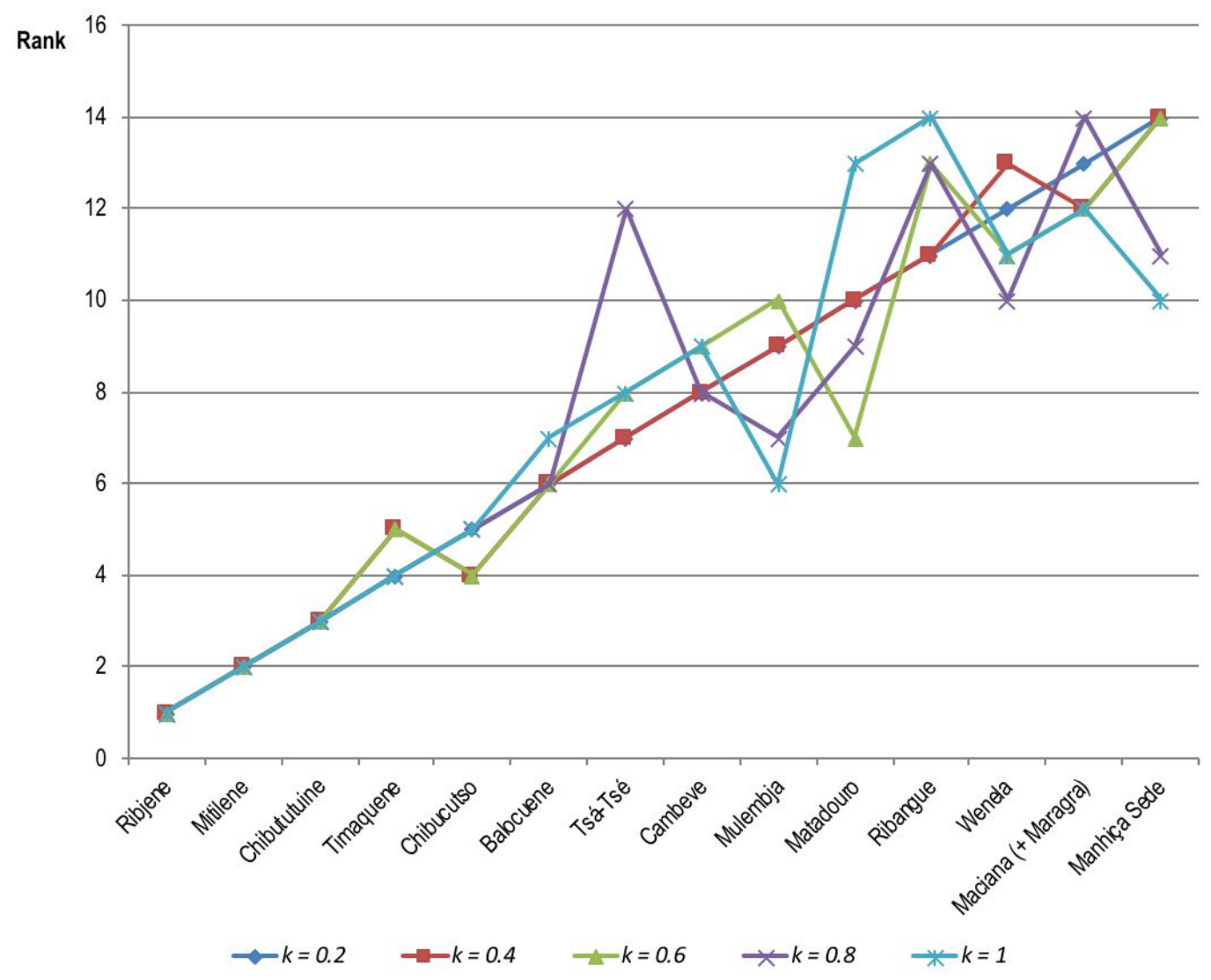

Figure 5 Effects of Multidimensional Poverty Cutoff Change on Ranks of Bairros (Deprivation Cutoff: Intermediate Service Level) 
395 Second, we analyse the impact of increasing the poverty cutoff on the headcount ratio $H$ and the 396 intensity of poverty $A$. As outlined previously, it is shown in Figure 8 that an increase in the poverty 397 cutoff leads to a different poverty context. For higher values of $k$, the intensity of sanitation poverty 10398 increases and is significantly higher compared to the headcount ratio of poor, which decreases with 11

the poverty cutoff. Having said this, it is observed that the poverty trend for all bairros is, to a certain extent, homogeneous.

Third, we vary the deprivation cutoff by considering two different levels of service - the good and intermediate. As with previous analyses, we rank bairros based on the $M_{0}$. Figure 9 shows that this test does not lead to significant changes in the rankings: only one bairro (Timaquene) moves up six places when the deprivation cutoff is altered.

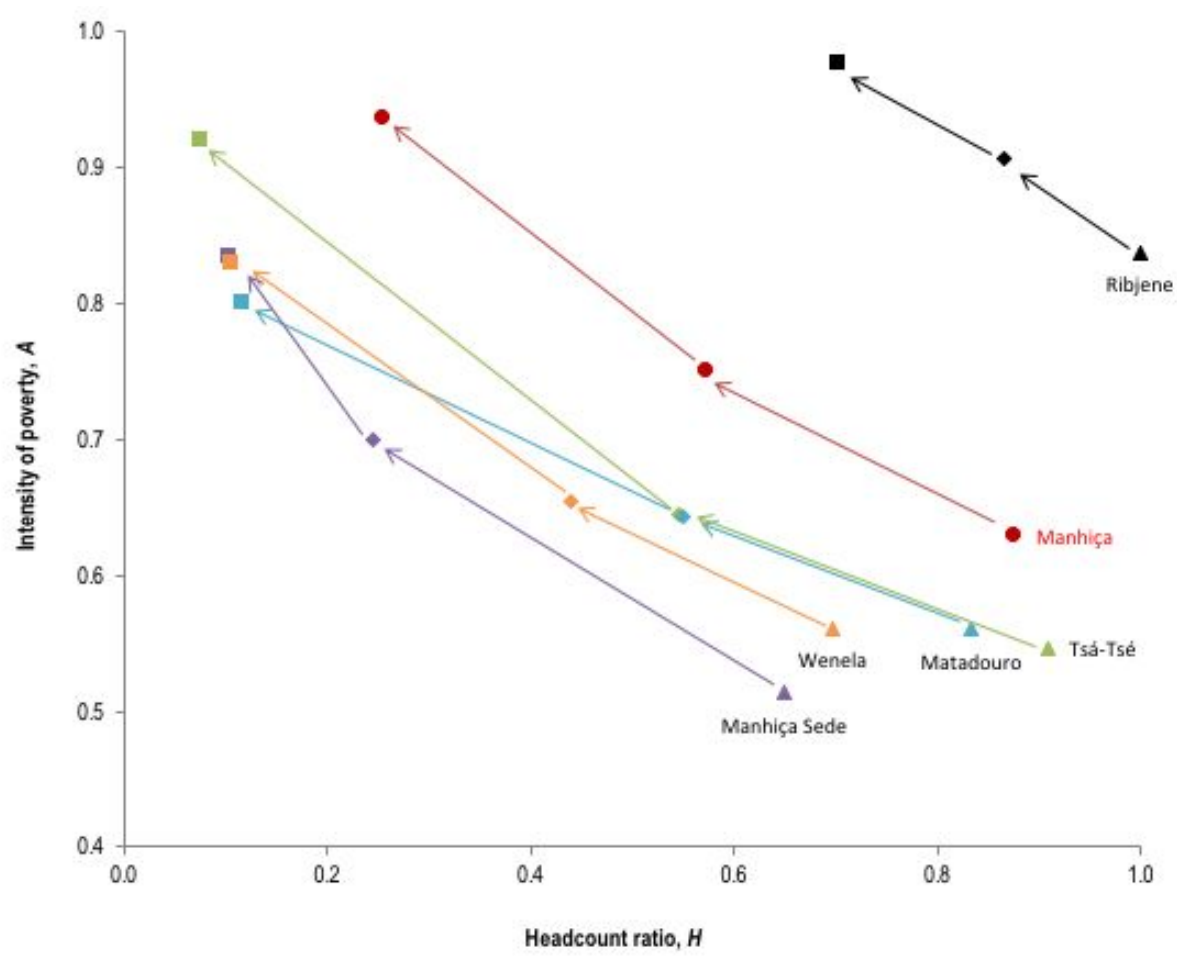

Figure 6 Effects of Multidimensional Poverty Cutoff Change on Headcount Ratio and on Intensity of Sanitation Poverty at Selected Bairros (Deprivation cutoff: Intermediate Service Level). Legend:

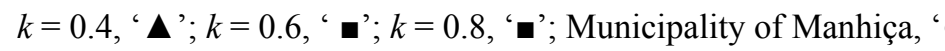




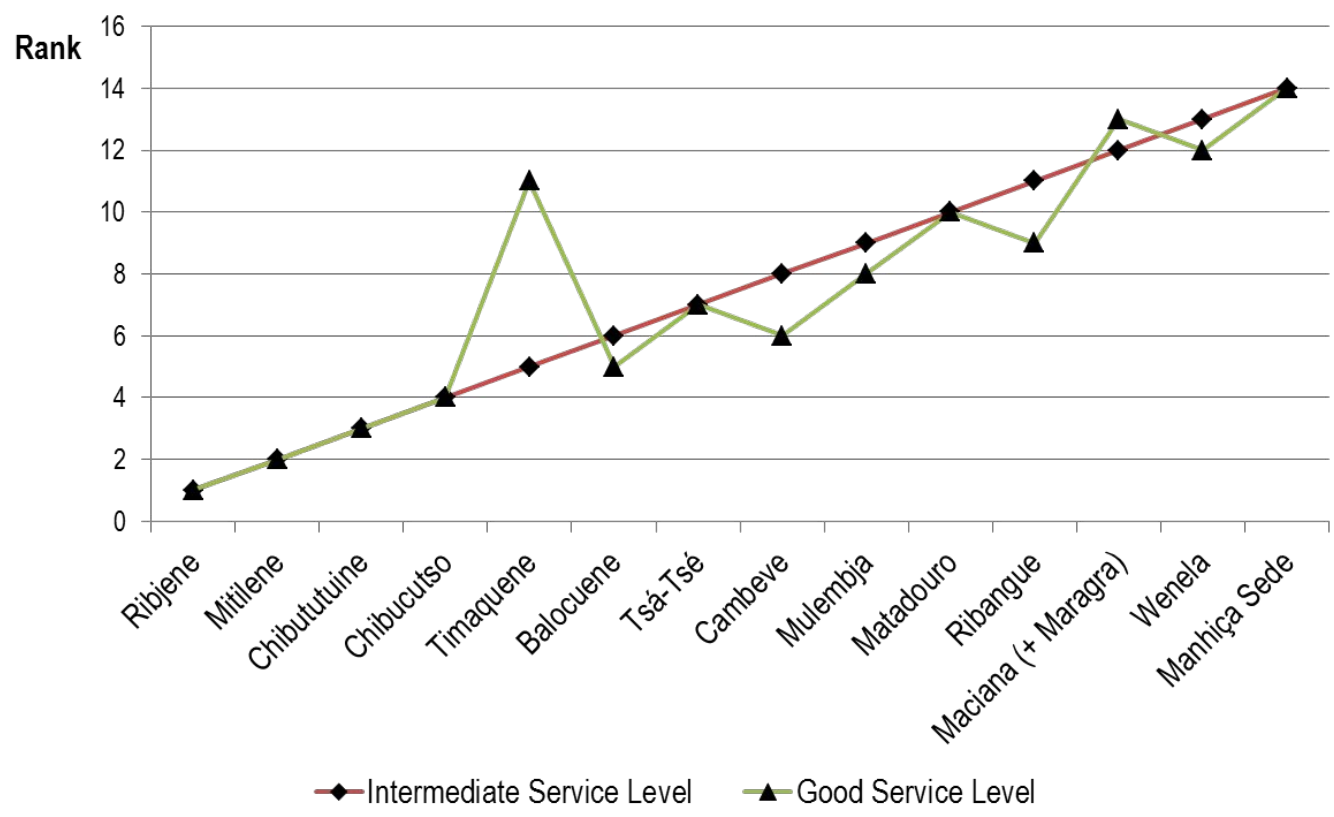

Figure 7: Effects of Multidimensional Deprivation Cutoff Change on Ranking of Bairros (Poverty cutoff $\mathrm{k}=0.4$ )

In sum, the robustness of the measure has been assessed for various poverty and deprivation cutoffs.

These tests help confirm that same policies and interventions would be supported across a range of plausible parameter specifications.

\section{Conclusions}

This paper presents and applies one new measure to evaluate water and sanitation poverty. It is based on the concept of multidimensional poverty and is inspired by the relevant literature. The method first applies a dual-cutoff approach to identification. The first is the dimension-specific deprivation cutoff, which identifies whether a person is deprived with respect to that dimension. The second is a poverty cutoff that is applied to the weighted sum of each person's deprivations. Each person is identified as poor if their deprivations are at or above the poverty cutoff level, and non-poor otherwise. The measure is therefore composed of two components: a measure of the incidence of poverty and a quantification of its intensity. 
427 In summary, achieved results demonstrate that applying a multidimensional analysis of poverty provides a number of advantages. First, the multidimensional measure focuses on the level of service and is based on data related to various attributes of WaSH services, as opposed to deriving information

\section{References}

Alkire, S., 2018. Multidimensional poverty measures as relevant policy tools (No. 118), OPHI Working Paper. Oxford.

Alkire, S., Foster, J., 2016. Dimensional and Distributional Contributions to Multidimensional Poverty (No. 100), OPHI Working Paper. Oxford.

Alkire, S., Foster, J., 2011. Counting and multidimensional poverty measurement. J. Public Econ. 95, 476-487. https://doi.org/10.1016/j.jpubeco.2010.11.006

Alkire, S., Foster, J., 2007. Counting and Multidimensional Poverty, OPHI Working Paper. Oxford. https://doi.org/10.2499/9780896296602BK

Alkire, S., Foster, J., Santos, M., 2011. Where did identification go? J. Econ. Inequal. 9, 501-505. 
https://doi.org/10.1007/s10888-011-9201-4

Alkire, S., Santos, M.E., 2014. Measuring Acute Poverty in the Developing World: Robustness and Scope of the Multidimensional Poverty Index. World Dev. 59, 251-274. https://doi.org/10.1016/j.worlddev.2014.01.026

Alkire, S., Santos, M.E., 2010. Acute Multidimensional Poverty: A New Index for Developing Countries, Oxford Poverty \& Human Development Initiative (OPHI) Working Paper. Oxford Department of International Development, University of Oxford, Oxford.

Anand, S., Sen, A., 1997. Concepts of Human Development and Poverty: A Multidimensional Perspective. Poverty Hum. Dev. Hum. Dev. Pap.

Baum, R., Luh, J., Bartram, J., 2013. Sanitation: A global estimate of sewerage connections without treatment and the resulting impact on MDG progress. Environ. Sci. Technol. 47. https://doi.org/10.1021/es304284f

Booysen, F., 2002. An Overview and Evaluation of Composite Indices of Development. Soc. Indic. Res. 59, 115-151. https://doi.org/10.1023/a:1016275505152

Bourguignon, F., Chakravarty, S., 2003. The measurement of multidimensional poverty. J. Econ. Inequal. 1, 25-49. https://doi.org/10.1007/978-0-387-79253-8

de Albuquerque, C., Roaf, V., 2014. Realising the Human Rights to Water and Sanitation: A Handbook by the UN Special Rapporteur. UN Special Rapporteur on the human right to safe drinking water and sanitation, Lisbon.

Ferreira, F.H.G.G., Lugo, M.A., 2013. Multidimensional poverty analysis: Looking for a middle ground. World Bank Res. Obs. 28, 220-235. https://doi.org/10.1093/wbro/lks013

Filmer, D., Pritchett, L.H., 2001. Estimating Wealth Effects without Expenditure Data-or Tears: An Application to Educational Enrollments in States of India. Demography 38, 115-132.

Flores Baquero, O., Gallego Ayala, J., Giné Garriga, R., Jiménez Fernández de Palencia, A., Pérez Foguet, A., 2017. The Influence of the Human Rights to Water and Sanitation Normative Content 
in Measuring the Level of Service. Soc. Indic. Res. 133, 763-786. https://doi.org/10.1007/s11205-016-1374-6

Flores Baquero, O., Jiménez, A., Pérez Foguet, A., 2013. Monitoring access to water in rural areas based on the human right to water framework: a local level case study in Nicaragua. Int. J. Water Resour. Dev. 29, 605-621. https://doi.org/10.1080/07900627.2012.757017

Flores Baquero, O., Jiménez Fdez. de Palencia, A., Pérez Foguet, A., 2015. Reporting progress on the human right to water and sanitation through JMP and GLAAS. J. Water, Sanit. Hyg. Dev. 5, 310_ 321. https://doi.org/10.2166/washdev.2015.151

Gallego-Ayala, J., Juízo, D., 2014. Integrating Stakeholders' Preferences into Water Resources Management Planning in the Incomati River Basin. Water Resour. Manag. 28, 527-540. https://doi.org/10.1007/s11269-013-0500-3

Giné-Garriga, R., Flores-Baquero, Ó., Jiménez-Fdez de Palencia, A., Pérez-Foguet, A., 2017. Monitoring sanitation and hygiene in the 2030 Agenda for Sustainable Development: A review through the lens of human rights. Sci. Total Environ. 580, 1108-1119. https://doi.org/10.1016/j.scitotenv.2016.12.066

Giné-Garriga, R., Jiménez, A., Pérez-Foguet, A., 2013. Water-sanitation-hygiene mapping: An improved approach for data collection at local level. Sci. Total Environ. 463-464, 700-711. https://doi.org/http://dx.doi.org/10.1016/j.scitotenv.2013.06.005

Giné-Garriga, R., Pérez-Foguet, A., 2013. Unravelling the Linkages Between Water, Sanitation, Hygiene and Rural Poverty: The WASH Poverty Index. Water Resour. Manag. 27, 1501-1515. https://doi.org/10.1007/s11269-012-0251-6

Giné-Garriga, R., Pérez-Foguet, A., 2011. Application of a revised Water Poverty Index to target the water poor. Water Sci. Technol. 63, 1099-1110. https://doi.org/10.2166/wst.2011.347

Giné-Garriga, R., Pérez-Foguet, A., 2010. Improved Method to Calculate a Water Poverty Index at Local Scale. J. Environ. Eng. 136, 1287-1298. https://doi.org/10.1061/(asce)ee.1943- 
$502 \quad 7870.0000255$

503 Gómez-Limón, J.A., Sanchez-Fernandez, G., 2010. Empirical evaluation of agricultural sustainability using composite indicators. Ecol. Econ. 69, 1062-1075. https://doi.org/https://doi.org/10.1016/j.ecolecon.2009.11.027

Grimm, M., Harttgen, K., Klasen, S., Misselhorn, M., 2008. A Human Development Index by Income Groups. World Dev. https://doi.org/10.1016/j.worlddev.2007.12.001

Hicks, D.A., 1997. The Inequality-Adjusted Human Development Index: A Constructive Proposal. World Dev. https://doi.org/10.1016/S0305-750X(97)00034-X

Houweling, T., Kunst, A., Mackenbach, J., 2003. Measuring health inequality among children in developing countries: does the choice of the indicator of economic status matter? Int. J. Equity Health 2, 8 .

Jiménez, A., Livsey, J., Åhlén, I., Scharp, C., Takane, M., 2018. Global assessment of accountability in water and sanitation services using GLAAS data. Water Altern. 11, 238-259.

Joint Monitoring Programme, 2017. Progress on Drinking Water, Sanitation and Hygiene: 2017 Update and SDG Baselines. Geneva.

Joint Monitoring Programme, 2015. JMP Green Paper: Global monitoring of water, sanitation and hygiene post-2015. New York and Geneva.

Joint Monitoring Programme, 2012. Final Report of the JMP Working Group on Equity and NonDiscrimination. WHO / UNICEF Joint Monitoring Programme for Water Supply and Sanitation (JMP), New York.

Luh, J., Baum, R., Bartram, J., 2013. Equity in water and sanitation: developing an index to measure progressive realization of the human right. Int. J. Hyg. Environ. Health 216, 662-671. https://doi.org/10.1016/j.ijheh.2012.12.007

Munda, G., 2012. Choosing Aggregation Rules for Composite Indicators. Soc. Indic. Res. 109, 337354. https://doi.org/10.1007/s11205-011-9911-9 
Munda, G., Nardo, M., 2005a. Non-Compensatory Composite Indicators for Ranking Countries: A Defensible Setting. Joint Research Centre - Institute for the Protection and Security of the Citizen, Ispra.

Munda, G., Nardo, M., 2005b. Constructing Consistent Composite Indicators: the Issue of Weights. Joint Research Centre - Institute for the Protection and Security of the Citizen, Ispra.

Nardo, M., Saisana, M., Saltelli, A., Tarantola, S., Hoffman, A., Giovannini, E., Directorate, O.S., 2005. Handbook on Constructing Composite Indicators: Methodology and User Guide, OECD Statistics Working Paper. OECD, Paris.

Njong, A., Ningaye, P., 2008. Characterizing weights in the measurement of multidimensional poverty: An application of data-driven approaches to Cameroonian data, OPHI Working Paper. Oxford.

Nussbaumer, P., Bazilian, M., Modi, V., 2012. Measuring energy poverty: Focusing on what matters. Renew. Sustain. Energy Rev. 16, 231-243. https://doi.org/10.1016/j.rser.2011.07.150

Pachauri, S., Spreng, D., 2011. Measuring and monitoring energy poverty. Energy Policy 39, 7497 7504. https://doi.org/10.1016/j.enpol.2011.07.008

Permanyer, I., 2011. Assessing the robustness of composite indices rankings. Rev. Income Wealth 57, 306-326. https://doi.org/10.1111/j.1475-4991.2011.00442.x

Ravallion, M., 2011. On multidimensional indices of poverty. J. Econ. Inequal. 9, 235-48. https://doi.org/10.1007/s10888-011-9173-4

Santos, E., Roche, J., Ballon, P., 2015. Robustness Analysis and Statistical Inference, in: Alkire, S., Foster, J.E., Seth, S., Santos, M.E., Roche, J., Ballon, P. (Eds.), Multidimensional Poverty Measurement and Analysis. Oxford University Press, Oxford, pp. 1-32.

Seth, S., McGillivray, M., 2018. Composite indices, alternative weights, and comparison robustness. Soc. Choice Welfare. https://doi.org/10.1007/s00355-018-1132-6

Sullivan, C.A., Meigh, J.R., Giacomello, A.M., Fediw, T., Lawrence, P., Samad, M., Mlote, S., Hutton, 
C., Allan, J.A., Schulze, R.E., Dlamini, D.J.M., Cosgrove, W., Priscoli, J.D., Gleick, P., Smout, I., Cobbing, J., Calow, R., Hunt, C., Hussain, A., Acreman, M.C., King, J., Malomo, S., Tate, E.L., O’Regan, D., Milner, S., Steyl, I., 2003. The water poverty index: Development and application at the community scale. Nat. Resour. Forum 27, 189-199.

The World Bank, 2017a. Reducing Inequalities in Water Supply, Sanitation, and Hygiene in the Era of the Sustainable Development Goals: Synthesis Report of the WASH Poverty Diagnostic Initiative. Washington D.C.

The World Bank, 2017b. Monitoring Global Poverty: Report of the Commission on Global Poverty. Washington DC. https://doi.org/10.1596/978-1-4648-0961-3

Tsui, K.Y., 2002. Multidimensional poverty indices. Soc. Choice Welfare 19, 69-93. https://doi.org/10.1007/s355-002-8326-3

UN Water, 2016a. Water and Sanitation Interlinkages across the 2030 Agenda for Sustainable Development. Geneva.

UN Water, 2016b. Monitoring Water and Sanitation in the 2030 Agenda for Sustainable Development. An introduction. Geneva, Switzerland.

United Nations, 2013. The Equitable Access Score-card: supporting policy processes to achieve the human right to water and sanitation. Geneva, Switzerland.

United Nations Children's Fund, 2006. Multiple Indicator Cluster Survey Manual 2005. UNICEF, Division of Policy and Planning, New York.

United Nations General Assembly, 2015a. Transforming our world: the 2030 Agenda for Sustainable Development. Resolution A/RES/70/1.

United Nations General Assembly, 2015b. The human rights to safe drinking water and sanitation. Resolution A/RES/70/169.

United Nations General Assembly, 2010a. The human right to water and sanitation. Resolution $\mathrm{A} / \mathrm{RES} / 64 / 292$. 
577 United Nations General Assembly, 2010b. Human rights and access to safe drinking water and sanitation. Resolution A/HRC/RES/15/9.

Victor, B., Blevins, M., Green, A.F., Ndatimana, E., González-Calvo, L., Fischer, E.F., Vergara, A.E., Vermund, S.H., Olupona, O., Moon, T.D., 2014. Multidimensional poverty in rural mozambique: A new metric for evaluating public health interventions. PLoS One 9. https://doi.org/10.1371/journal.pone.0108654

World Health Organization, 2017. UN-Water global analysis and assessment of sanitation and drinking-water (GLAAS) 2017 report: financing universal water, sanitation and hygiene under the sustainable development goals, WHO. Geneva. https://doi.org/CC BY-NC-SA 3.0 IGO. 